\title{
Walk Long and Prosper: What Is the Optimal Way to Help People Achieve Their Goals?
}

\author{
Jeffrey S. Hoch, $P h D^{1,2}$ and Carolyn S. Dewa, MPH, $P h D^{3,4}$ \\ 'Department of Public Health Sciences, University of California, Davis, CA, USA; ${ }^{2}$ Center for Healthcare Policy and Research, University of California, \\ Davis, Sacramento, CA, USA; ${ }^{3}$ Department of Psychiatry, University of California, Davis, Sacramento, CA, USA; ${ }^{4}$ Behavioral Health Center of \\ Excellence, University of California, Davis, Sacramento, CA, USA.
}

J Gen Intern Med 31(7):712-3

DOI: $10.1007 / \mathrm{s} 11606-016-3709-Z$

(C) Society of General Internal Medicine 2016

I $\mathrm{n}$ this month's issue of the JGIM, Patel and colleagues ${ }^{1}$ report the results of a randomized controlled trial (RCT) with the goal of increasing the activity of sedentary US employees assigned to one of four reimbursement schemes. Over the 13-week intervention period, four-person teams were eligible for prizes based on achieving 7000 steps. Qualification for a prize was dependent on the reimbursement plan into which they were assigned. These included 1) \$0 (control group), 2) $\$ 50$ if the 7000 step goal was reached by the individual (individual incentive), 3) \$50 if the 7000 step goal was reached by all team members (team incentive) or 4) \$20 for reaching an individual goal of 7000 steps $+\$ 10$ for every other team member reaching the goal (combined incentive). Receipt of a prize was contingent on winning a lottery that was held every other day during which a team from each of the four reimbursement plans was selected and paid according to its performance on the prior day.

The article reports two major findings: 1) the combined incentive plan (i.e., reimbursement based on the combined performance of both the individual and the team members) was the most effective and 2) through time, the 7,000-step achievement waned regardless of the reimbursement scheme. The authors interpret these results as suggesting that the use of both individual and team incentives (i.e., a combined incentive plan) can boost performance.

We would like to offer our observations about these results. First, incentives must sufficiently cover the costs of the activity that they seek to encourage. ${ }^{2}$ For example, the individual incentive group (i.e., the group with the most potential to gain financially) was not relatively more likely to achieve the 7,000 step goal. One explanation could be that the monetary incentive was weak compared to the time cost (non-monetary disincentive) it would have taken to reach the goal. This begs the question, "How large a monetary incentive is necessary to change the specific behavior that it seeks to modify?"

Published online April 25, 2016
Second, reimbursement structures can have unintended consequences. For example, the authors observed that the combined incentive group totaled an average of just over 21,000 steps. $^{1}$ This 21,000 total step average is also consistent with a team using a designated non-walker arrangement. This could have happened if the combined incentive reimbursement scheme encouraged scheduled shirking. That is, team members could have agreed to work together to reach the common goal of getting the greatest pay-off with the least effort. This could have been done if all four members agreed to rotate who takes a day off from walking. This means only three members walked but the day's designated non-walker did not. In addition, those who walked needed to take at least 7000 steps to achieve a team total of 21,000 steps and $\$ 120$ in reimbursement. Without knowledge of this arrangement, it would appear that only the designated walkers received payment. But, in reality, the team could allocate the total reward to everyone including the designated non-walker. Thus, both walkers and non-walkers could have been rewarded.

In contrast, the team incentive model was supposed to enhance individuals' accountability to teammates. Ultimately, this would lead to a common goal among all team members. If teamwork were the overriding motivation for participants in this study, we would have expected to see the team incentive producing the most steps. But, this was not the case. In fact, the team incentive arm of the study averaged only one step more than the control arm averaged during the 13 weeks (3930 vs. 3929 steps).

For team incentive reimbursement plans, walking is only rewarded if everyone achieves 7000 steps. All it takes is for one person to fail for the team financial incentive to become equivalent to that of the control arm. This is the case because the under-achievers are not identifiable. If one's team is given a $\$ 0$ reward for its performance, it is common knowledge to those who walked that at least one person did not walk 7000 steps. But, it is not clear who failed. As a result, the impact of the accountability incentive is diluted. This suggests that without some accountability, the team incentive is not particularly effective.

At the same time it should be noted that although there was no difference between the team incentive and control arms, the control groups did receive an intervention. This lack of difference could be a consequence of the fact that the "intervention" 
received by the control groups was as effective as the team incentive. Control arm participants received daily feedback on performance towards achieving a daily 7000 step goal during the intervention by email, text message, or automated voice call. Indeed, other studies have observed changes in behavior related to daily reminders. ${ }^{3}$ As a result, these results also raise the question of how feedback could be optimized to achieve behavior change.

Third, it is not clear that reimbursement based on a lottery system is always optimal. The use of a lottery may inadvertently encourage people to take less action. After all, a reward is not a sure thing even if someone goes to the trouble of achieving the goal. In addition, there is less of an incentive to walk if all days are not eligible for the lottery.

Finally, these study results also lead us to wonder about the relative effectiveness of offering a pay-out as a potential gain versus a potential loss. For example, in another study, Patel et al. ${ }^{4}$ looked at the same primary outcome. The difference was the incentive structure. In that study, they found that financial incentives framed as a loss (i.e., where the reward is provided to all and then taken away from those failing to achieve the goal) were effective for achieving physical activity goals. Future research could examine which of these two approaches has greater influence on different types of behavioral change - the proverbial carrot or the stick.

This study by Patel et al. ${ }^{1}$ explored different incentive schemes to encourage people to walk $\geq 7000$ steps. It highlights the role of incentives in behavior change and the application of economics. This study demonstrates how insights from economics have the potential to help people. We propose four take-away lessons: (1) incentives must sufficiently cover the costs of the activity that they seek to encourage; (2) reimbursement structures can have unintended consequences; (3) reimbursement based on a lottery system may not always be optimal; and (4) it is not clear whether potential gain or potential loss incentives are more effective. In addition, the surprising results are reminders of how important it is to consider the complexity of influencing behavior changes and how incentives can be used to motivate them.

Corresponding Author: Jeffrey S. Hoch, PhD; Center for Healthcare Policy and ResearchUniversity of California, Davis, School of Medicine, Sacramento, CA, USA (e-mail: jshoch@ucdavis.edu).

Conflict of interest: The authors declare that they do not have a conflict of interest.

\section{REFERENCES}

1. Patel MS, Asch DA, Rosin R, Small DS, Bellamy SL, Eberbach K, Walters KJ, Haff N, Lee SM, Wesby L, Hoffer K, Shuttleworth D, Taylor DH, Hilbert V, Zhu J, Yang L, Wang X, Volpp KG. Individual versus team-based financial incentives to increase physical activity: a randomized, controlled tria. J Gen Intern Med. 2016. doi:10.1007/s11606-016-3627-0.

2. Patel MS, Asch DA, Troxel AB, Fletcher M, Osman-Koss R, Brady J, Wesby L, Hilbert V, Zhu J, Wang W, Volpp KG. Premium-based financial incentives did not promote workplace weight loss in a 2013-15 study. Health Aff (Millwood). 2016;35(1):71-9.

3. Fischer HH, Fischer IP, Pereira RI, Furniss AL, Rozwadowski JM, Moore SL, Durfee MJ, Raghunath SG, Tsai AG, Havranek EP. Text message support for weight loss in patients with prediabetes: a randomized clinical trial. Diabetes Care. 2016. doi:10.2337/dc15-2137.

4. Patel MS, Asch DA, Rosin R, Small DS, Bellamy SL, Heuer J, Sproat S, Hyson C, Haff N, Lee SM, Wesby L, Hoffer K, Shuttleworth D, Taylor DH, Hilbert V, Zhu J, Yang L, Wang X, Volpp KG. Framing financial incentives to increase physical activity among overweight and obese adults: a randomized, controlled trial. Ann Intern Med. 2016;164(6):385-94. 